\title{
Review on Biological Techniques, Microbial Food Testing Approaches, Biosensors Principles and Applications
}

\author{
Uzma Nasrullah $^{1 *}$ Umair Ishfaq $^{2}$, Mahpara Qamar ${ }^{3 *}$, Muhammad Azam ${ }^{4}$, Wajahat Zahra Naqvi ${ }^{3}$, Hamza Rafeeq ${ }^{3}$, Zainab \\ Noor $^{3}$ \\ ${ }^{1}$ Department of Botany, University of Agriculture Faisalabad, Pakistan \\ ${ }^{2}$ National Institute of Food Science and Technology, University of Agriculture, Faisalabad, Pakistan \\ ${ }^{3}$ Department of Biochemistry, University of agriculture Faisalabad, Pakistan \\ ${ }^{4}$ Institute of Microbiology, University of Agriculture Faisalabad, Pakistan
}

DOI: $10.36348 / \mathrm{sb} .2021 . v 07 \mathrm{i} 04.003$

| Received: 24.01.2021 | Accepted: 08.02.2021 | Published: 13.04.2021

*Corresponding author: Mahpara Qamar

\section{Abstract}

In the body with the high specificity and the sensitivity the ability of to detect the physiological and the pathogenic related molecules offers a opportunity which is very powerful and helpful in the treatment of the disease with the early diagnosis. The optical base biosensor in which the optical fiber cable is used in the different research and in many other medical fields. Bacteriophages are ubiquitous viruses, found wherever bacteria exist. It is estimated there are more than $10^{31}$ bacteriophages on the planet, more than every other organism on earth, including bacteria, combined. In recent years it has become widely recognized that bacteriophages have several potential applications in the food industry. They have been proposed as alternatives to antibiotics in animal health, as biopreservatives in food and as tools for detecting pathogenic bacteria throughout the food chain. Phages play a key role in maintaining microbial balance in every ecosystem where bacteria exist, and they are part of the normal microflora of all fresh, unprocessed foods. Interest in various practical applications of bacteriophages has been gaining momentum recently, with perhaps the most attention focused on using them to improve food safety.

Keywords: Bacteriophages, Food safety, techniques, Food nutrition, biological testing.

Copyright () 2021 The Author(s): This is an open-access article distributed under the terms of the Creative Commons Attribution 4.0 International License (CC BY-NC 4.0) which permits unrestricted use, distribution, and reproduction in any medium for non-commercial use provided the original author and source are credited.

\section{INTRODUCTION}

It is well known that biosensors play very important role in the detection of the biological molecule and have been working under development more than for over to 35 years and more than 15 years ago that in this field of area the research become very popular. The oldest one breed of the biosensor was the biosensor of the electrochemical and the glucose analyte detector was the only biosensor which achieved the success at commercial level and some of the perspective of the which is biosensor for expectations and science funding and lot of big difference in the gap in the commercial and academic achievement of the bio sensor $[1,2]$.

In the body with the high specificity and the sensitivity the ability of to detect the physiological and the pathogenic related molecules offers a opportunity which is very powerful and helpful in the treatment of the disease with the early diagnosis. The many diseases can be can control with the help of early diagnosis and patient get cured and have minimum chances of the cost of patients which is related to the many advance stages of disease [3-5].

Bacteriophages are among the most common and diverse entities in the biosphere. Bacteriophages are ubiquitous viruses, found wherever bacteria exist. It is estimated there are more than $10^{31}$ bacteriophages on the planet, more than every other organism on Earth, including bacteria, combined. Viruses are the most abundant biological entity in the water column of the world's oceans, and the second largest component of biomass after prokaryotes, where up to $9 \times 10^{8}$ virions per millilitre have been found in microbial mats at the surface, and up to $70 \%$ of marine bacteria may be infected by phages[6,7]. 
In recent years it has become widely recognized that bacteriophages have several potential applications in the food industry. They have been proposed as alternatives to antibiotics in animal health, as biopreservatives in food and as tools for detecting pathogenic bacteria throughout the food chain. Bacteriophages are viruses that only infect and lyse bacterial cells. Consequently, they display two unique features relevant in and suitable for food safety. In the era of the development of organic foods and with rising awareness of healthy eating, non-chemical measures for food protection are becoming increasingly popular. Phage cocktails meet all the criteria to be recognized as a green technology for combating food-borne pathogenic and spoilage bacteria [8-10].

Food is the primary route of transmission for more than 200 known diseases. The leading bacterial food-borne pathogens of concern are Salmonella, Campylobacter, Shiga toxinproducing E. coli, and Listeria monocytogenes [3]. Each of them can be associated with serious gastrointestinal infections. Food-borne diseases remain a major cause of hospitalization and death worldwide, despite many advances in modern technologies including food sanitation techniques and pathogen surveillance [11].

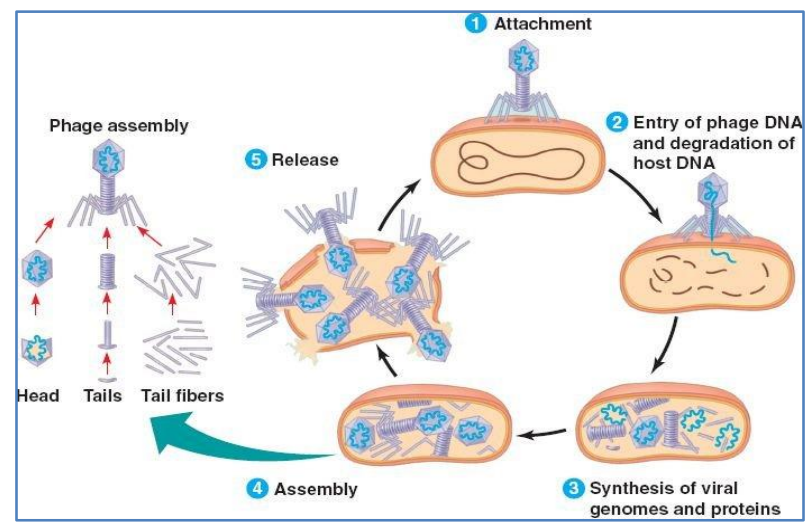

Fig-1: Shows the nature and mechanism of action of bacteriophages

\section{Application of Bacteriophages in Food Industries}

Bacteriophages are viruses that infect and lyse bacteria. Interest in the ability of phages to control bacterial populations has extended from medical applications into the fields of agriculture, aquaculture and the food industry. Bacteriophages (also called 'phages') are viruses that kill bacteria. They are arguably the oldest (3 billion years old, by some estimates) and most ubiquitous (total number estimated to be 10(30) 10(32) known organisms on Earth. Phages play a key role in maintaining microbial balance in every ecosystem where bacteria exist, and they are part of the normal microflora of all fresh, unprocessed foods. Interest in various practical applications of bacteriophages has been gaining momentum recently, with perhaps the most attention focused on using them to improve food safety [12].

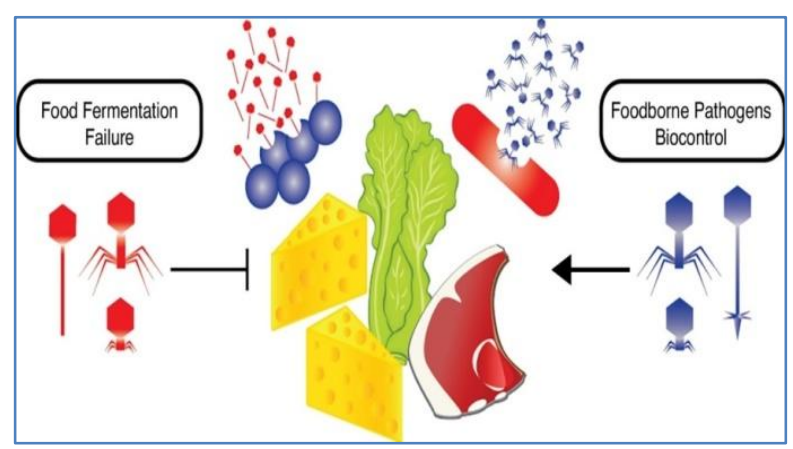

Fig-2: Shows the applications of bacteriophages in food industries

In the bio sensor system the 20 medically different fluids is often determine by the help of the test based on electrochemical detection. Just example a test is performed which is highly specific which take place between the reagent and the analyte and that is mostly of the enzyme based and in this reaction the stage of oxidation of the enzyme may change. The concentration of the analyte which play important role in the changing of the reaction and changing take place in the reaction which mean the charge is transfer on the surface of the electrodes and the DC voltage is applied to the electrode to just measure the charge transfer on the surface of the electrodes $[13,14]$.

The classification of the biosensor on the base of the bio signaling mechanism in which the signal is utilized for detection and any other types of the bio sensors which is given below.

\section{Biological signal based biosensor}

This type of biosensor in which the biological recognition or bioreceptors element is highly significant features of the biosensors and the biosensor consist of the sensor which sense and recognize the element in the solution and target get achieved. Normally this is very crucial for the bioreceptors to be a sensitive and selective for their specific kind of target that may be any analyte and mostly this prevent from any kind of interference by some other molecule or substance which is present in the matrix sample. Normally the classification of the biosensor on the base of the biological signal or the mechanism used by that specific molecule and there are the five major mechanism on which the biological signals can be divided [15].

\section{Enzyme Based biosensor}

The first biosensor was based on the enzyme and that was firstly introduced by the Lyon and Clark around 1962 which is an amperometric in nature and the enzyme which is placed on the electrode for the detection of the glucos. From than to now the enzyme based bio sensor have the great applications and enzymes are protein in nature and act as a catalyst and 
Uzma Nasrullah et al., Sch Bull, Apr, 2021; 7(4): 82-86

for each of the enzyme the specific substrate and converted into transformation in the form of product, and enzymes which is use as the very powerful tool for the detection of the various substance. For the detection Michaelis menten equation is used and GOD glucoseoxidase and the HRP horse reddish peroxidase are the enzyme both of these enzymes used in the detection in the biosensor which is reported in the various literature. There are many other enzyme used to detect the cholesterol, monitoring of the environment, food quality, heavy metals and the pesticides [16-18].

\section{Nucleic acid /DNA based biosensor}

The early use of the DNA/ Nucleic acid sequence in the diagnostic applications started in the 1953 and growing in the positive way. The high affinity of each of the single standard DNA of the Double standard DNA is used in the biosensor of the nucleic acid and the nucleic acid element use as the recognition. DNA based sensnor promote the development of new methods for the coupling of the some electrophoretic separations and other separations which is at high cost such as the radio isotropic and are the very consuming [19].

Nucleic acid biosensor work on the base of the hydrogen bonding between the one strand of the DNA that make interaction with the new coming DNA molecule which bind with each other give the signals in the form of the fluorescence which glow up and indicated that reaction is completed. To make complete this reaction a probe is used which act as the complementary DNA which makes interaction with the single standard DNA molecule. The hybridization is completed between the probe and the ssDNA in the result a biochemical reaction take place in which reaction allow to amplify the signals that is converted into electrical signals[20,21,22].

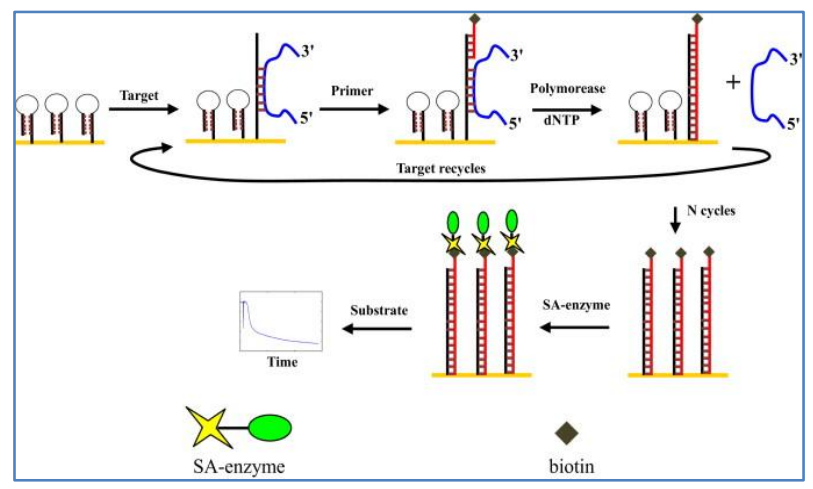

Fig-3: Shows the components and principle of nucleic acids based biosensors

\section{Bio transducers based}

The classification of the biosensor has been done on the basis of the transduction method which they follow to complete their action. In the bio sensor a system or the component is present which play very important role in the detection of the signals and amplify that signals significantly that its can be measure easily so definition of the transducer can be the it the instrument or the system which convert the biological, physiological and the chemical signal into the detectable form such as the electrochemical signals which show the maximum sensitivity and the very less chance of the disturbance in the measurement [23-25].

\section{Electrochemical Based}

Electrochemical based biosensor is based on the principle in which an electrode is attached which acts as the transducer that detects the signal and amplify this which can be easily measured and this is very important subclass of the biosensor [26, 27]. In the 1999 with the recommendation electrochemical device is the self, contained and is integrated device in which biological signals can act as a analyte give information in the quantitative or the semi quantitative[28, 29].

\section{Optical based transducer}

In the recent years there are many advances take place in the field of the optical bio sensor and many other important other areas such as the safety of the food, environment monitoring, medicine, and the life science [30, 31]. The plasmonreson surface and the fluorescence that is attached with the optical and this most popular method for the bio sensing of the optical. The optical base biosensor in which the optical fiber cable is used in the different research and in many other medical fields $[32,33]$.

\section{CONCLUSION}

Biological techniques are used to study living things. They include experimental and computational methods, approaches, protocols and tools for biological research. The goals of biotechnology is to produce drugs by using living organisms such as bacterial cells, yeast, mammalian cells, etc., that are placed in culture to produce substances with pharmacological activity, such as monoclonal antibodies for the treatment of tumors.

\section{REFERENCES}

1. Savickas, S., Kastl, P., \& auf dem Keller, U. (2020). Combinatorial degradomics: Precision tools to unveil proteolytic processes in biological systems. Biochimica et Biophysica Acta (BBA)Proteins and Proteomics, 1868(6), 140392.

2. Riser-Roberts, E. (2020). Remediation of petroleum contaminated soils: biological, physical, and chemical processes. CRC press.

3. Birk, S., Bonne, W., Borja, A., Brucet, S., Courrat, A., Poikane, S., \& Hering, D. (2012). Three hundred ways to assess Europe's surface waters: an almost complete overview of biological methods to implement the Water Framework Directive. Ecological indicators, 18, 31-41.

4. Meo, S. A., Alhowikan, A. M., Al-Khlaiwi, T., Meo, I. M., Halepoto, D. M., Iqbal, M., \& Ahmed, 
N. (2020). Novel coronavirus 2019-nCoV: prevalence, biological and clinical characteristics comparison with SARS-CoV and MERS-CoV. Eur Rev Med Pharmacol Sci, 24(4), 2012-2019.

5. Costantini, I., Cicchi, R., Silvestri, L., Vanzi, F., \& Pavone, F. S. (2019). In-vivo and ex-vivo optical clearing methods for biological tissues. Biomedical optics express, 10(10), 5251-5267.

6. Graziano, S., Anzillotti, L., Mannocchi, G., Pichini, S., \& Busardò, F. P. (2019). Screening methods for rapid determination of new psychoactive substances (NPS) in conventional and nonconventional biological matrices. Journal of pharmaceutical and biomedical analysis, 163, 170179.

7. Nagarajan, D., Kusmayadi, A., Yen, H. W., Dong, C. D., Lee, D. J., \& Chang, J. S. (2019). Current advances in biological swine wastewater treatment using microalgae-based processes. Bioresource technology, 289, 121718.

8. Zeng, L., Gao, J., Liu, Y., Gao, J., Yao, L., Yang, X. ... \& Jiang, G. (2019). Role of protein corona in the biological effect of nanomaterials: Investigating methods. TrAC Trends in Analytical Chemistry, 118, 303-314.

9. Shahid, A., Ali, S., Zahra, T., Raza, M., Shahid, A., Saeed, M. U., \& Javaid, F. Influence of Microbes in Progression of Cancer and DNA Damaging Effects.

10. Iftikhar, A., Shahid, A., Shah, S. S., Ali, S., Raza, M., Ali, E., \& Umbreen, S. Antimicrobial Activities of Selected Medicinal Plant with Potential Role of Chemical Compounds.

11. Qamar, M., Mustafa, G. A., Tariq, S., Rafeeq, H., Rafiq, M., Naqvi, W. Z., \& Kanwal, T. Novel Methods for Detection of Biological Samples, Current Direction and Future Perspectives.

12. Naeem, M., Hayat, M., Qamar, S. A., Mehmood, T., Munir, A., Ahmad, G., \& Hussain, A. (2019). Risk factors, genetic mutations and prevention of breast cancer. Int. J. Biosci, 14(4), 492-496.

13. Shafiq, S., Adeel, M., Raza, H., Iqbal, R., Ahmad, Z., Naeem, M., \& Azmi, U. R. (2019). Effects of Foliar Application of Selenium in Maize (Zea Mays L.) under Cadmium Toxicity. In Biological Forum-An International Journal, 11(2): 27-37.

14. Ahmad, I., Khan, S., Naeem, M., Hayat, M., Azmi, U. R., Ahmed, S., \& Irfan, M. (2019). Molecular Identification of Ten Palm Species using DNA Fingerprinting. Int. J. Pure App. Biosci, 7(1), 4651.

15. Usman, G., Muhammad, N., Hamza, R., Usman, I., Ayesha, A., Saqib, U., \& Fatima, Q. (2019). A Novel Approach towards Nutraceuticals and Biomedical Applications. Scholars International Journal of Biochemistry, 2(10), 245-252.

16. Tahir, M. F., Ali, S., Noman, M., \& Goher, M. A Novel Approach towards the Potential Effects of
Chlorpyrifos on Testicular Biochemistry and Physiology of Male Sprague Dawely Rats.

17. Naeem, M., Ali, J., Hassan, M. Z., Arshad, B., Rao, M. H. I., Sarmad, M. S. K., \&amp; Hassan, M. U. (2019). Novel Approach towards DNA Barcoding as a Tool in Molecular Biologyand Biological Activities of Cyclotides with Particular Emphasizes at Molecular Level. In Biological Forum-An International Journal, 11(2), 83-96.

18. Naeem, A., Saddique, S., \& Chand, S. A. (2019). Advancement and Future Directions towards Herbal Treatment for Various Diseases.

19. Naeem, M., Ashraf, A., Safdar, H. M. Z., Khan, M. Q., Rehman, S. U., Iqbal, R., \& Ahmad, G. (2020). Biochemical changes in patients with chronic kidney failure in relation to complete blood count and anemia. IJB, 16(1), 267-271

20. Naeem, M., Hussain, A., Azmi, U. R., Maqsood, S., Imtiaz, U., Ali, H., \& Ghani, U. (2019). Comparative Anatomical Studies of Epidermis with Different Stomatal Patterns in Some Selected Plants Using Compound Light Microscopy. International Journal of Scientific and Research Publications, 9(10), 375-380.

21. Ahsan, M., Aslam, M., Akhtar, M. A., Azmi, U. R., Naeem, M., Murtaza, G., \& Shafiq, S. (2019). Effect of inoculation of three rhizobial strains on maize hybrids. Journal of Biodiversity and Environmental Sciences, 14(6), 168-177.

22. Hazafa, A., Batool, A., Ahmad, S., Amjad, M., Chaudhry, S. N., Asad, J., \& Ghani, U. (2020). Humanin: A mitochondrial-derived peptide in the treatment of apoptosis-related diseases. Life Sciences, 264, 2021, 118679.

23. Khan, S., Abbas, A., Ali, I., Arshad, R., Tareen, M. B. K., \& Shah, M. I. (2019). Prevalence of overweight and obesity and lifestyle assessment among school-going children of Multan, Pakistan.

24. Rafeeq, H., Ahmad, S., Tareen, M. B. K., Shahzad, K. A., Bashir, A., Jabeen, R., \& Shehzadi, I. Biochemistry of Fat Soluble Vitamins, Sources, Biochemical Functions and Toxicity. Haya: The Saudi Journal of Life Sciences

25. Ghani, U., Naeem, M. Bukhari, S.S.H., Yar, G., Tariq, I., Siddique, S., Nawaz, H.A., Pal, Z.A.A., Nasim, F., and Bukhari, S.A.H. (2019). Prevalence and Risk Factors associated with Hepatitis B and Hepatitis $\mathrm{C}$ and their Correlation with Inflammatory Markers among Southern Region of Punjab. Biological Forum - An International Journal, 11(2): 136-143.

26. Khan, S., Zelle Rubab, S. H., Abbas, A., Arshad, R., \& Tareen, M. B. K. Hematological profile of children with severe acute malnutrition at the Tertiary care hospital in Multan.

27. Muhammad, N., Umair, R.A., Sarmad, A.Q., Ahmad, M. T. M., Muhammad, A. F. (2019). Reliable vaccine production by using Risk Based Bioengineering Strategies. 6th International 
Conference on "Sustainable Agriculture in Changing Climate: Strategies and Management. 261.

28. Smits, A. H., Ziebell, F., Joberty, G., Zinn, N., Mueller, W. F., Clauder-Münster, S., \& Huber, W. (2019). Biological plasticity rescues target activity in CRISPR knock outs. Nature methods, 16(11), 1087-1093.

29. Hou, R., Li, Y., Sui, Z., Yuan, H., Yang, K., Liang, Z., \& Zhang, Y. (2019). Advances in exosome isolation methods and their applications in proteomic analysis of biological samples. Analytical and bioanalytical chemistry, 411(21), 5351-5361.

30. Brodbelt, J. S., Morrison, L. J., \& Santos, I. (2019). Ultraviolet photodissociation mass spectrometry for analysis of biological molecules. Chemical reviews, 120(7), 3328-3380.

31. Zhang, K., Xu, R., Abomohra, A. E. F., Xie, S., Yu, Z., Guo, Q., \& Li, X. (2019). A sustainable approach for efficient conversion of lignin into biodiesel accompanied by biological pretreatment of corn straw. Energy Conversion and Management, 199, 111928.

32. Nasrollahzadeh, M., Sajadi, S. M., Issaabadi, Z., \& Sajjadi, M. (2019). Biological sources used in green nanotechnology. In Interface Science and Technology (Vol. 28, pp. 81-111). Elsevier.

33. Sharma, H. K., Xu, C., \& Qin, W. (2019). Biological pretreatment of lignocellulosic biomass for biofuels and bioproducts: an overview. Waste and Biomass Valorization, 10(2), 235-251. 